\title{
AVALIAÇÃO DA IMAGEM QUE OS FRANCESES TÊM DO BRASIL COMO SEDE DE MEGAEVENTOS
}

\author{
EVALUATION OF THE IMAGE HELD BY THE FRENCH TOWARDS BRAZIL AS A HOST \\ COUNTRY FOR MEGA-EVENTS
}

EVALUACIÓN DE LA IMAGEN QUE LOS FRANCESES TIENEN DEL BRASIL
COMO SEDE DE MEGA EVENTOS

Giovanna Buischi Antunes Olivieri
Bacharel em Administração Faculdade de Economia, Administração e Contabilidade da
Universidade de São Paulo (FEARP/USP)
gibuischi@gmail.com

Janaina de Moura Engracia Giraldi

Professora do Departamento de Administração da FEARP/USP, Doutora em Administração pela USP

jgiraldi@usp.br

Luciana Brandão Ferreira

Professora do Departamento de Turismo e Hotelaria da Universidade Federal do Maranhão, Doutoranda no Programa de Administração das Organizações da FEARP/USP

Bolsista FAPEMA

bfluciana@gmail.com

Data de Submissão: 10/05/2017

Data de Aceitação: 29/08/2017

RESUMO: O Brasil recebeu grandes eventos nos últimos anos, como Jornada Mundial da Juventude, Rio +20 e especialmente megaeventos esportivos, como a Copa do Mundo de Futebol, e mais recentemente os Jogos Olímpicos de 2016. Baseado nesse contexto e na importância desses eventos, sobretudo para a imagem do destino que os recebe, esse estudo objetivou avaliar a imagem do destino turístico Brasil como sede de megaeventos. Para isso, foi realizada uma pesquisa quantitativa descritiva com aplicação de questionários eletrônicos com uma amostra de estudantes franceses. Após a coleta dos dados, uma análise fatorial exploratória e uma comparação de médias entre as dimensões resultantes foram realizadas. Os resultados indicaram que os estudantes franceses possuem uma imagem positiva do Brasil como sede de grandes eventos, sendo os "Pontos Turísticos" a dimensão de imagem de destino mais bem apreciada. Adicionalmente, verificou-se que gênero e experiência com o país não foram fatores que influenciaram as respostas da amostra.

PALAVRAS-CHAVE: Imagem de Destino Turístico. Imagem do Brasil. Megaeventos.

\begin{abstract}
Brazil has hosted mega-events in recent years, such as World Youth Day, Rio +20, and in particular, sports events such as the Football World Cup and more recently, the 2016 Olympic Games. Based on that context, and on the importance of these events, especially for tourist destination image, this study evaluates the image of Brazil as a tourist destination that hosts mega-events. A descriptive, quantitative study was carried out, though the application of electronic questionnaires distributed to a sample of French students. After the data collection, exploratory factorial analysis and comparison of means were performed. The results indicated that the French students had a positive image of Brazil as a mega-events host country, and that "Tourism Points" was the dimension of destination image most appreciated. It was also found that sex and previous experience of the country did not influence the students' responses.
\end{abstract}

KEYWORDS: Tourist Destination Image. Image of Brazil. Mega-events. 
RESUMEN: Brasil recibió grandes eventos en los últimos años, como la Jornada Mundial de la Juventud, Rio +20 y especialmente mega eventos deportivos, como la Copa del Mundo de Fútbol, y más recientemente los Juegos Olímpicos de 2016. Basado en ese contexto y en la importancia de esos eventos, sobre todo para la imagen del destino que los recibe, este estudio tuvo el objetivo de evaluar la imagen del destino turístico Brasil como sede de mega eventos. Para ello fue realizada una investigación cuantitativa descriptiva con la aplicación de cuestionarios electrónicos con una muestra de estudiantes franceses. Tras la recolección de los datos, se llevó a cabo un análisis factorial exploratorio y una comparación de medias entre las dimensiones resultantes. Los resultados indicaron que los estudiantes franceses poseen una imagen positiva de Brasil como sede de grandes eventos, siendo los "Puntos Turísticos" la dimensión de imagen de destino mejor apreciada. Adicionalmente, se verificó que género y experiencia con el país no fueron factores que influyeron sobre las respuestas de la muestra.

PALABRAS CLAVE: Imagen de Destino Turístico. Imagen del Brasil. Mega eventos.

\section{INTRODUÇÃO}

ventos culturais de larga escala, comerciais ou esportivos são
chamados de megaeventos exatamente por possuírem grande
apelo popular e significância internacional (Roche, 2000). Entre os megaeventos esportivos, alguns exemplos de alta expressividade são a Copa do Mundo de Futebol e os Jogos Olímpicos (Davies, 2009). Para Fourie \& Gallego (2011), esses eventos, além de atraírem uma público-alvo mundial e estabelecerem padrões globais de turismo, apresentam novos destinos e criam legados duradouros para os locais sede. Por sua grande abrangência, o estudo de grandes e megaeventos é um assunto que tem instigado trabalhos que destacam tanto impactos positivos quanto negativos. Alguns estudos (Moon, Kim, Jae Ko, Connaughton \& Hak Lee, 2011; Moon, Jae Ko, Connaughton \& Lee, 2013; Du Plessis \& Maenning, 2011; Knott, Fyall \& Jones (2015); Swart, George, Cassar \& Sneyd (2017) destacam que os megaeventos movimentam a economia do turismo, possibilitam melhorar a infraestrutura e mudar a imagem mundial do país, como também influenciar as intenções de visitá-lo.

No caso de aspectos negativos, Tavares (2005) ressalta que a realização de megaeventos esportivos apresenta, por vezes, um saldo sócio-políticoeconômico inferior ao imaginado, amplia polarização e desigualdade social. Li, Blake e Cooper (2011) também indicam que, em geral, os impactos econômicos são superestimados. No entanto, apesar dos custos e dos benefícios, sejam eles tangíveis ou intangíveis, permanecerem em debate, tem-se dado foco ultimamente em aspectos dos megaeventos que são quantificáveis, como 
comportamento do turista (Fourie \& Gallego, 2011). Na Copa do Mundo de 2010, a África do Sul recebeu 310 mil turistas estrangeiros, a Alemanha em 2006 recebeu 2 milhões, em 2002 o Japão recebeu 400 mil turistas, em 1998 a Copa do Mundo de Futebol levou à França 500 mil turistas e em 1994, 400 mil aos Estados Unidos (Lima, 2014). Apesar de ter sido um pouco menos que o esperado, o Brasil recepcionou 6,4 milhões de turistas internacionais em 2014, sendo a Copa do Mundo a responsável pelo recorde histórico e pelo aumento de 10,6\% em relação ao ano anterior (Brasil, 2015). Nos Jogos Olímpicos de 2016, foi registrada a entrada de 410 mil turistas estrangeiros só no Rio de Janeiro $(G 1,2016)$.

De acordo com Fourie e Gallego (2011), existem ganhos significantes durante o ano em que um megaevento ocorre. O que inclui turistas específicos que visitam o país para o evento, como também turistas não participantes que mudam de comportamento e vão ao país em outra época do mesmo ano. Um dos aspectos intangíveis defendidos pela literatura é o impacto positivo desses eventos na imagem do país como destino turístico. Knott et al. (2015) enfatizam a influência dos megaeventos na imagem do destino turístico. $O$ estudo dos impactos de imagem é uma vertente da literatura, com significante aumento de publicações na última década, possuindo relevância acadêmica e prática e sendo um importante aspecto na avaliação de eventos (Dragin-Jensen, 2016).

O conceito de imagem de destinos turísticos é definido por diversos autores, como impressões sobre países em que as pessoas não residem; soma de atributos relacionados com a experiência de turismo; percepção do indivíduo sobre as características do destino; efeitos de crenças, ideias e impressões que uma pessoa possui sobre um destino (Elliot, Papadopoulos \& Kim, 2011; Tasci \& Kozak, 2006). Muitos autores (Moon et al., 2011; Moon et al., 2013; Roth; Diamantopoulos, 2009; Matos, Mendes \& Valle, 2012) consideram que o construto imagem de destino é composto por três dimensões relacionadas: o componente cognitivo, as crenças em relação ao país; o componente afetivo, as emoções que o indivíduo tem com o país; e o componente conativo, as intenções comportamentais para com o país. A importância de investir em uma boa imagem deve-se ao fato de ser um aspecto relevante na intenção entre turistas atuais e potenciais de visitar o local (Tasci, Gartner \& Cavusgil, 2007; Rezend-Parker, Morrison \& Ismail, 2003). 
Vários autores indicam que o contexto de realização de megaeventos, especialmente os esportivos, influencia na imagem de destinos e consequentemente na decisão de visitá-los (Berkowitz, Gjermani, Gomez \& CSchafer, 2007; Walker, Kaplanidou, Gibson, Thapa, Geldenhuys \& Coetzee, 2013; Deng \& Li, 2013; Lee, Lee \& Lee, 2005a; Kaplanidou \& Vogt, 2007). Por isso, é importante identificar como os destinos são percebidos em relação à sua capacidade de realização desse tipo de evento. Assim, estudar a imagem do país como destino que recebe um megaevento é relevante por contribuir tanto com a literatura de imagem de destino, quanto sobre impactos de megaeventos. Também contribui de forma gerencial com informações que podem auxiliar o desenvolvimento de estratégias para realização de novos megaeventos. Nesse sentido, o objetivo desse trabalho foi identificar a imagem que os franceses possuem do Brasil como destino sede de um megaevento. Para tanto, foi realizada uma pesquisa quantitativa descritiva com estudantes franceses, por meio de questionários estruturados. O público escolhido para a pesquisa está entre os 10 maiores países emissores de turistas internacionais ao Brasil, sendo o principal país do continente europeu (Brasil, 2017). Para a análise das dimensões de imagem, foram utilizadas as variáveis: situação política, cultura, segurança e pontos turísticos, consideradas por vários autores como participantes da formação da imagem de um destino turístico e da avaliação do indivíduo na decisão de ir ou não visitá-lo (Nadeau, Heslop, O’Reilly, Luk, 2008; Elliot et al., 2011; Korstanje, Tzanelli \& Clayton, 2014; Tomlinson, Bass \& Bassett, 2011; Melo \& Mataruna, 2016; Lee et al., 2005a; Durand, 2016).

\section{IMAGEM DE DESTINOS COMO SEDES DE MEGAEVENTOS}

O enriquecimento da imagem de um destino que recebe um megaevento é em grande parte dirigido pela capacidade do mesmo de atrair a atenção da mídia internacional que, por sua vez, pode influenciar as avaliações que são feitas sobre ele (Lee et al., 2005a). Assim, em grande parte os eventos possuem um papel positivo em impactar a imagem dos destinos, como também aumentar consciência e familiaridade, reduzir imagens negativas e fornecer associações positivas (Dragin-Jensen, 2016). 
A percepção dos visitantes é formada pelos níveis de consciência e pela imagem do destino sede, como também por informações externas da mídia e agências do governo, que almejam interagir com fatores individuais, conhecimentos do próprio indivíduo, valores e experiências passadas (Kim et al., 2006). Pesquisas sobre imagem de destinos turísticos, como a realizada na Copa da Coréia de 2002 (Lee et al., 2005a), revelam que percepções sobre lugares para grandes eventos provocam antecedentes em como as pessoas interpretam suas experiências no local. A análise da imagem da Coréia do Sul antes e depois de sediar as Olimpíadas de 1988 indicou que pessoas com alta exposição aos jogos tiveram uma melhora geral sobre a imagem do país (Jaffe \& Nebenzahl, 1993).

Dessa forma, de acordo com o efeito de alavanca estratégica de imagens mostradas ao mundo, em conjunto com o evento (antes, durante e depois), o nível de consciência sobre um país/cidade pode ser elevado, permitindo aos eventos destacarem aspectos do destino aos potenciais visitantes, beneficiando sua imagem (Dragin-Jensen, 2016). Isso pode impulsionar, também, uma visita em algum momento no futuro ou informar o mundo sobre uma localidade específica (Gibson, Qi \& Zhang, 2008).

Contudo, em relação à preparação para um megaevento, os organizadores não podem assumir que sediá-lo, automaticamente trará benefícios. É necessário verificar a percepção do país anfitrião e os desafios que precisam ser superados do ponto de vista de um turista esportivo (Bresler, 2011). Um deles é o risco de que hospedar o megaevento não promova a imagem desejada (Gibson et al., 2008) ou que não afete/ mude a imagem do país (Nadeau et al., 2008). Para se impactar positivamente a imagem de destino e causar aumento da visitação, a mudança deve ser positiva e ocorrer ao longo das dimensões de imagem de destino, como desenvolvimento do ambiente, segurança, clima, conveniência ou ambiente familiar, que são importantes para os viajantes (Gibson et al., 2008).

Roth \& Diamantopoulos (2009) destacam que definição de imagem global de país é um constructo genérico de imagem, composto, dentre outros fatores, pelas tradições e pela cultura do país. Verlegh, Althuijzen \& Vroegh (1999) definem que a cultura de um país pode se tornar uma crença para a formação 
ISSN: 1983-7151

de seu estereótipo. Os autores Balabanis, Mueller e Melewar (2002) também pontuam que alguns dos antecedentes de imagem de país de origem são cultura e valores humanos. Do mesmo modo, o contexto PEST (político, econômico, sociocultural e tecnológico) de um país tem papel central como influência de antecedentes e moderadores, influenciando a imagem de país e a exibição de informações do país (Durand, 2016).

Em se tratando do Brasil, um ponto negativo, assim como para a África do Sul, é a existência de problemas organizacionais e estrutura pobre para sediar megaeventos esportivos internacionais. Um problema comum entre as doze cidades sede da Copa no Brasil era a falta de capacidade aeroportuária para lidar com o fluxo de visitantes previsto para 2014, visto que os aeroportos operavam perto de sua capacidade máxima (De Melo, 2011). Além disso, havia ainda o foco da mídia em ângulos negativos do Rio de Janeiro, por haver problemas contínuos de violência, retratando aspectos do crime organizado, com vários confrontos militares ocorrendo nas favelas (Tomlinson et al., 2011).

Mudando para o lado positivo, a pesquisa realizada pelos autores Melo e Mataruna (2016), em Munique, com estrangeiros que nunca vieram ao Brasil, revelou que os entrevistados possuem uma imagem positiva sobre o país. Os respondentes mencionaram alguns dos estereótipos relacionados ao Brasil, às cidades, à cultura, à natureza, ao esporte e à cozinha, como Rio de Janeiro, São Paulo, Cristo Redentor, Copa Cabana, Rio Amazonas, praias e futebol. Apesar de a maioria das palavras mencionadas em relação ao Brasil terem sido positivas, algumas negativas apareceram com menor frequência, sendo elas pobreza e crime. Também foi citada a palavra favela, que pode ser facilmente relacionada às áreas pobres do Rio de Janeiro. Contudo, ainda são recentes e em menor número as pesquisas realizadas no âmbito da imagem do Brasil, sobretudo relacionando com megaeventos (Da Silva, Braga, Romano, 2016), destacandose assim a importância deste estudo para a teoria de turismo no Brasil.

\section{DESENVOLVIMENTO DAS HIPÓTESES DA PESQUISA}

Megaeventos esportivos podem mudar a imagem do destino turístico sede (Lee et al., 2005a), aumentar a consciência e reduzir imagens negativas (DraginJensen, 2016). Um dos impactos positivos é o efeito de sensibilização, que é 
uma implementação da percepção internacional por estrangeiros do país sede e seus participantes (Du Plessis \& Maenning, 2011). Assim, ações promocionais não podem ser consideradas como as únicas soluções para atingir uma imagem de destino forte e real, mas também se devem analisar as necessidades e as características do mercado-alvo, como motivação e personalidade, e a imagem do país no exterior (Matos, Mendes \& Valle, 2012). Logo, a principal hipótese deste estudo é:

- Hipótese 1: Os franceses possuem uma imagem positiva do Brasil como um país sede de grandes eventos.

Observa-se que atributos estudados em pesquisas de imagem são crenças sobre o ambiente natural, atrações, cenário, clima, cultura, sociedade moderna, afabilidade, avaliações do destino como excitante e emocionante, e avaliação global (Nadeau et al., 2008). As campanhas orientadas para o turismo geralmente focam em características do país (Elliot et al., 2011); paisagem, cultura e economia de um país podem se tornar crenças para a formação de seu estereótipo (Verlegh et al., 1999). Alguns estereótipos em relação ao Brasil retratam um país festivo, como também com extrema violência e pobreza (Tomlinson et al., 2011); sendo assim, caracterizado por fortes contrastes, mas se prevalecendo, apesar disso, um país que oferece uma imagem relacionada à paz e à prosperidade (Korstanje et al., 2014).

Com relação às dimensões que compõem a imagem do Brasil, Nadeau et al. (2008) definem que os destinos são vulneráveis a alguns riscos, como agitação política, podendo a instabilidade política afetar negativamente avaliações sobre o local, de acordo com as crenças em relação ao país e às pessoas. A política interna do Brasil foi retratada pela mídia mostrando problemas como reivindicações sindicais dos trabalhadores e ameaça de greve na véspera e durante a Copa do Mundo (Korstanje et al., 2014), assim como nos Jogos Olímpicos, com a maior operação anticorrupção (Operação Lava Jato) do país e inúmeras manifestações da população (The New York Times, 2016). Por outro lado, algumas mudanças também podem servir para melhorar a imagem do país, por exemplo, a eleição de Dilma Rousseff em 2010 destacou o Brasil como um dos poucos países a ter uma liderança feminina (Tomlinson et al., 2011). 
Em relação à "segurança", a mídia cobria constantemente o ângulo negativo do Rio de Janeiro (cidade sede do Jogos Olímpicos) por existirem problemas contínuos de violência (Tomlinson et al., 2011). Mas, por outro lado, a maioria das palavras mencionadas em relação ao Brasil, na pesquisa de Melo \& Mataruna (2016) foi positiva, apesar de algumas negativas que apareceram com menor frequência.

A dimensão "cultura" também se mostra importante na formação da imagem do Brasil. Futebol, carnaval e samba foram as palavras mais citadas por todos os entrevistados, enfatizando música e festivais como elementos da imagem cultural brasileira; também a figura da população brasileira apareceu como uma das imagens do país, quando mencionaram pessoas amigáveis e pessoas legais (Melo \& Mataruna, 2016). Festejar e celebrar durante o carnaval depois de um jogo de futebol ou na vida cotidiana são imagens familiares sobre os brasileiros (Tomlinson et al., 2011). Os "pontos turísticos" mostramse uma dimensão relevante na decisão de turistas e na imagem de destinos, sendo alguns considerados por turistas: atmosfera, cenário e atrações naturais (Lee, Taylor, Lee \& Lee, 2005b). Alguns dos estereótipos em relação ao Brasil mencionados pelos respondentes em pesquisa foram relacionados à cultura, às cidades, à natureza e ao esporte (Melo \& Mataruna, 2016). Considerando as explicações apresentadas nos parágrafos anteriores, as hipóteses 2 e 3 são:

- Hipótese 2: A imagem do Brasil é composta pelas dimensões situação política, segurança, cultura e pontos turísticos.

- Hipótese 3: A dimensão pontos turísticos é a dimensão mais bem apreciada na avaliação da imagem do Brasil como sede de um megaevento esportivo.

Com relação aos determinantes da imagem de país, de acordo com Balabanis et al. (2002), eles são baseados nas características do país avaliado e nas diferenças demográficas dos observadores, como gênero, idade, renda e educação. Sabe-se que existem diferenças entre os sexos, mas não são notadamente significativas (Beerli \& Martín, 2004), carecendo de mais estudos. Portanto, a hipótese 4 é apresentada como:

- Hipótese 4: As pessoas do sexo feminino avaliam a imagem do Brasil como sede de grandes eventos mais positivamente do que as pessoas do sexo masculino. 
Quanto à familiaridade/experiência com o destino, estudos de imagem de destinos turísticos mostram que, quanto mais se é familiar com um destino, mais positiva é a percepção sobre ele; tendo ainda uma maior significância e positividade se não for a primeira visita do turista ao local (Elliot et al., 2011). A variável experiência com o país também é um fator relacionado ao conhecimento do indivíduo que aumenta a objetividade e a realidade da percepção sobre o país (Balabanis et al., 2002; Durand \& 2016). Dessa forma, a hipótese 5 é:

- Hipótese 5: As pessoas que possuem maior experiência com o Brasil avaliam a imagem desse destino como sede de grandes eventos mais positivamente do que as pessoas com menor experiência.

\section{METODOLOGIA}

Para atingir o objetivo, foi realizada uma pesquisa quantitativa descritiva que, de acordo com Malhotra (2012), é um tipo conclusivo e possui como objetivo principal a descrição de algo. Esta pesquisa considera imagem de destino como o principal construto para análise, composto por três dimensões: cognitiva, afetiva e conativa (Moon et al., 2011, Moon et al., 2013; Roth \& Diamantopoulos, 2009). Para a análise dessas dimensões de imagem, foram utilizadas as variáveis: (1) situação política, (2) cultura, (3) segurança e (4) pontos turísticos, consideradas por vários autores como participantes da formação da imagem de um destino turístico e da avaliação do indivíduo na decisão de ir ou não visitar o país (Nadeau et al., 2008; Elliot et al., 2011; Korstanje et al., 2014; Tomlinson et al., 2011; Melo \& Mataruna, 2016; Lee et al., 2005b; Durand, 2016). A coleta de dados foi feita por meio de questionário estruturado, aplicado eletronicamente, com questões em uma escala intervalar de sete pontos (tipo Likert).

Foram também coletadas variáveis demográficas como gênero e idade para descrição da amostra e da realização de comparações. Variáveis demográficas são consideradas por alguns estudiosos como impactantes em diferenças de avaliações e opiniões sobre um país ou seus produtos (Balabanis et al., 2002). A variável experiência com o país também foi analisada, pois, segundo alguns autores (Balabanis et al., 2002; Durand, 2016), é um fator relacionado 
ao conhecimento do indivíduo que aumenta a objetividade e a realidade da percepção sobre o país.

A população-alvo da pesquisa foram estudantes universitários franceses. 0 período da coleta foi entre agosto e setembro de 2016. Cabe destacar aqui que, nesse período, os Jogos Olímpicos já tinham acontecido, podendo a amostra ter tido mais contato com informações sobre o Brasil e conhecimento de resultados em relação ao megaevento. O arcabouço amostral utilizado para representar os elementos da população-alvo da pesquisa contou majoritariamente com o grupo no Facebook da Faculdade Kedge Business School, de Marseille, França, sendo usada uma amostragem não probabilística por conveniência. Com relação ao tamanho da amostra, observando-se alguns dos artigos utilizados como base teórica (Moon et al., 2011; Moon et al., 2013; Gibson et al., 2008, 2008; Lee et al., 2005a; Elliot et al., 2011), foi considerado o número de 100 respondentes como um número mínimo para se realizarem as análises estatísticas no programa SPSS (análise fatorial exploratória e comparação de médias).

\section{APRESENTAÇÃO E DISCUSSÃO DOS RESULTADOS}

A amostra foi composta por 107 questionários válidos. Com relação ao perfil, a média de idade foi de 22 anos com faixa etária de 17 a 25 anos. A amostra incluiu pessoas de ambos os sexos com percentuais bastante similares $(54,7 \%$ feminino e $45.3 \%$ masculino). A nacionalidade dos participantes é francesa e todos são estudantes universitários.

\section{ANÁLISE FATORIAL EXPLORATÓRIA NAS QUESTÕES SOBRE IMAGEM DO BRASIL}

De acordo com Hair et al. (2009), alguns parâmetros devem ser observados para que uma análise seja validada. Para tanto, foi utilizado o método Kaiser Kaiser-Meyer-Olkin (KMO). O valor do KMO, para ser admirável, precisa ser maior ou igual a 0,8; se for maior ou igual a 0,7 é mediano, menor que 0,5 não é aceitável. Ainda segundo os autores, a decisão sobre o número de fatores a serem 
mantidos na análise se deve à quantidade ser suficiente para o atendimento de uma variância explicada de $60 \%$ ou mais. Como também, no quesito das variáveis, deve-se manter as que possuem comunalidades maiores que 0,5. Para tanto, foram realizadas cinco rodadas, sendo a quinta a mais significativa e com os fatores mais bem explicados. Na quarta rodada da análise fatorial observou-se que 6 variáveis possuíam valores menores que 0,5 na matriz de comunalidades, sendo assim excluídas na quinta rodada.

A Tabela 1 apresenta o índice $\mathrm{KMO}$ e a significância encontrados na análise final. O KMO quantifica o grau de intercorrelação entre as variáveis e a adequação da análise fatorial, sendo que quanto mais perto de 1 , mais perfeita é a previsão sem erro de uma variável pelas outras (HAIR et al., 2009). Dessa forma, a análise apresenta um KMO de 0,808, sendo classificado como ótimo e considerado estatisticamente significante.

Tabela 1 - Teste de Esfericidade de Bartlett e KMO para as questões de imagem do Brasil

Teste de Bartlett e KMO

Kaiser-Meyer-Olkin

Teste de Esfericidade de Bartlett
Medida de Adequação da amostra

Qui- Quadrado Aproxim.

gl

Sig.
0,808

1011,381

190

0,000

Fonte: Autoras, 2016.

Foram obtidos 5 fatores, que explicam 67,08\% da variância total dos elementos, conforme mostra a Tabela 2. Um resultado satisfatório segundo Hair et al. (2009).

Tabela 2 - Variância total explicada pelos fatores

Eigenvalues iniciais

Componentes

Total

6,289

3,024

1,610

1,349

1,143

0,840

0,710

0,648
\% Variância

31,447

15,121

8,052

6,746

5,717

4,199

3,548

3,242
Cumulativo \%

31,447

46,567

54,619

61,366

67,083

71,282

74,830

78,072 


\begin{tabular}{c|ccc}
9 & 0,612 & 3,059 & 81,132 \\
10 & 0,572 & 2,860 & 83,992 \\
11 & 0,528 & 2,642 & 86,633 \\
12 & 0,458 & 2,289 & 88,922 \\
13 & 0,439 & 2,196 & 91,118 \\
14 & 0,380 & 1,898 & 93,016 \\
15 & 0,324 & 1,619 & 94,635 \\
16 & 0,279 & 1,393 & 96,028 \\
17 & 0,244 & 1,219 & 97,246 \\
18 & 0,199 & 0,997 & 98,243 \\
19 & 0,186 & 0,930 & 99,173 \\
20 & 0,165 & 0,827 & 100,000 \\
\hline
\end{tabular}

Fonte: Autoras, 2016.

A Tabela 3 apresenta os fatores resultantes da análise, bem como as variáveis que os compõem. Para a decisão de a que fator cada variável pertence, foi identificada a maior carga que a variável possui (em valor absoluto), sendo a variável pertencente ao fator para o qual ela possuir maior carga (Hair et al., 2009).

Tabela 3 - Matriz de componentes rotacionada

Matriz de componentes rotacionados

A beleza natural do Brasil é de tirar o fôlego

Vale a pena ficar mais dias no Brasil para visitar os pontos turísticos

Os turistas podem se sentir seguros nos estabelecimentos de grandes eventos

Os políticos do Brasil são honestos

O povo brasileiro é amigável e receptivo

O Brasil é um país seguro

A cultura do Brasil me deixa animado

Eu gostaria de visitar o Brasil

Os turistas podem se sentir seguros em pontos turísticos

O povo brasileiro é confiável

A situação política do Brasil me deixa confiante de que o país possui a capacidade de sediar um evento

A frequência de roubos e assaltos no Brasil é baixa

O povo brasileiro é trabalhador

Eu possuo uma imagem positiva do Brasil como um destino turístico $\begin{array}{ccccc}\text { Visão } & \text { Situação } & \text { Segurança } & \text { Cultura } & \begin{array}{c}\text { Pontos } \\ \text { Turísticos }\end{array} \\ \text { generalista } & \text { Política } & \text { S } & & \end{array}$

0,818

0,269

0,810

$0,212 \quad 0,755 \quad 0,252$

, 789

$-0,218$

0,334

0,499

0,449

$0,335 \quad 0,377 \quad \mathbf{0 , 5 3 0} \quad 0,376$

0,696

0,457

0,696

0,469

0,312

0,763

$\mathbf{0 , 7 6 4} \quad 0,231$

$0,225 \quad \mathbf{0 , 7 0 1} \quad 0,243$

$0,377 \quad \mathbf{0 , 4 9 1} \quad 0,384$

0,813

0,728

0,299 
A segurança é um fator significante ao se decidir ir ao Brasil para um grande evento

Todo dinheiro destinado à construção de estruturas para sediar eventos é bem utilizado para esse fim

A cultura brasileira instiga apreço

O Brasil aumenta a segurança durante grandes eventos

A cultura do Brasil incentiva ir ao país para um grande evento
0,228

$-0,695$

0,205

0,767

0,665

0,395

0,636

0,337

0,342

0,785

0,700

0,246

Fonte: Autoras, 2016.

Observa-se que o Fator 1 é composto por sentenças pertencentes às três dimensões da imagem do Brasil como sede de megaeventos propostas inicialmente, cultura, pontos turísticos e segurança; e explica 31,4\% da variância total dos elementos. Suas sentenças são: "A cultura do Brasil incentiva ir ao país para um grande evento", "O Brasil aumenta a segurança durante grandes eventos", "A cultura brasileira instiga apreço", "Eu possuo uma imagem positiva do Brasil como um destino turístico", "Eu gostaria de visitar o Brasil" e "A cultura do Brasil me deixa animado". Observa-se que o Fator 1 possui variáveis que são geralmente aplicadas à imagem do Brasil, visto que a cultura, os pontos turísticos e a segurança do país são assuntos muito recorrentes nos meios em que se fala sobre ele, sendo então nomeado como "Visão Generalista" do país. De acordo com Tomlinson et al. (2011), um dos estereótipos que retrata o Brasil é o de um país com violência e lutas contínuas entre o crime organizado e a polícia. Porém, em meio a essa violência, o Brasil sediou com sucesso os Jogos Pan Americanos de 2007, podendo ser um indício de que o país se preocupa com a segurança dos turistas e busca reforçá-la durante megaeventos. Segundo a pesquisa de Melo e Mataruna (2016), alguns dos estereótipos mencionados em relação ao Brasil pelos pesquisados enfatizavam elementos da cultura brasileira e seus pontos turísticos.

O Fator 2 explica 15,1\% da variância total dos dados e é composto somente por variáveis pertencentes à situação política, uma das dimensões de imagem propostas. Suas sentenças são: "Os políticos do Brasil são honestos", "A situação política do Brasil me deixa confiante de que o país possui a capacidade para 
sediar um evento", "Todo dinheiro destinado à construção de estruturas para sediar eventos é bem utilizado para esse fim" e "A situação política do Brasil não influencia o país ser a sede de grandes eventos". Podendo dessa forma receber o nome da dimensão que foi proposta nesse estudo como participante da imagem do Brasil, "Situação Política" do país. Os destinos são vulneráveis a riscos, como agitação política, os quais podem afetar as avaliações (Nadeau et al., 2008). Mostra-se, assim, a relevância do fator situação política do país para sua avaliação como destinação turística e sede de um megaevento.

O Fator 3 explica $8,05 \%$ da variabilidade total dos elementos analisados e é composto por variáveis pertencentes à dimensão segurança, apenas com as sentenças: "Os turistas podem se sentir seguros nos estabelecimentos de grandes eventos", "O Brasil é um país seguro", "Os turistas podem se sentir seguros em pontos turísticos", "A frequência de roubos e assaltos no Brasil é baixa" e "A segurança é um fator significante ao se decidir ir ao Brasil para um grande evento". De acordo com Gibson et al. (2008), estudiosos possuem um consenso de que proteção e segurança são pré-requisitos para fluxos consistentes de turistas e comércio em geral durante megaeventos. Em busca de uma imagem positiva de destinação, como também um aumento da visitação, países devem buscar implementar dimensões de imagem de destino, como segurança e conveniência ou ambiente familiar. Na pesquisa de Melo \& Mataruna (2016), alguns dos entrevistados mencionaram crime como uma palavra relacionada ao Brasil. Ainda segundo os autores, a intenção de visitar o país durante os Jogos Olímpicos de 2016 também pode estar relacionada a aspectos como segurança e infraestrutura. Assim, a nomeação do Fator 3 foi de "Segurança" do país, visto sua importância na realização de megaeventos e na avaliação de uma destinação turística, como também na formação da imagem do Brasil.

O Fator 4 explica 6,7\% da variância total dos dados e é composto pelas sentenças "O povo brasileiro é amigável e receptivo", "O povo brasileiro é confiável" e "O povo brasileiro é trabalhador". Todas as sentenças são pertencentes à dimensão cultura da imagem do Brasil, sendo o Fator 4 nomeado de "Cultura" do país. Especificamente na área de turismo desportivo, em relação a sediar um megaevento, imagens gerais da destinação relacionadas à cultura e às pessoas são parte do processo de prever as intenções de frequentar os 
Jogos (Gibson et al., 2008). Dessa forma, mostra-se a relevância do fator cultura na construção de imagem de país e do mesmo como destino turístico.

O Fator 5 explica 5,7\% da variabilidade total dos elementos analisados e possui como variáveis "A beleza natural do Brasil é de tirar o folego" e "Vale a pena ficar mais dias no Brasil para visitar os pontos turísticos". Sendo composto somente por variáveis da dimensão pontos turísticos, leva o nome de "Pontos Turísticos" do país. Esta se mostra uma dimensão relevante na decisão de destinos por turistas e na imagem de destinos, sendo alguns segmentos de imagem considerados por turistas: atmosfera, cenário e atrações naturais (Lee et al., 2005b). Após a realização da análise fatorial exploratória, foi possível identificar as dimensões que compõem a imagem do Brasil como sede de megaeventos, verificando a Hipótese 2 (A imagem do Brasil é composta pelas dimensões situação política, segurança, cultura e pontos turísticos). Conforme a análise realizada, as dimensões de imagem do Brasil propostas de acordo com os fatores resultantes foram: "Visão Generalista", "Situação Política", "Segurança", "Cultura" e "Pontos Turísticos". Assim, as quatro dimensões inicialmente sugeridas puderam ser identificadas e outra dimensão surgiu, englobando pontos que geralmente são relacionados ao Brasil e às variáveis que levam a uma interpretação mais global do país, não entrando especificamente em um quesito em especial da formação da imagem. Logo, pode-se dizer que a Hipótese 2 foi parcialmente confirmada, concluindo-se que houve uma similaridade entre as dimensões de imagem de destino derivadas da amostra utilizada e aquelas identificadas nas teorias de imagem de destino apresentadas na revisão da literatura, demonstrando um suporte teórico para os resultados empíricos do trabalho.

Interessante ressaltar ainda o fato de que a "Situação política" foi um fator mais forte que a "Segurança", apesar desta última ser considerada bastante relevante pela literatura como pré-requisito para a existência de fluxos turísticos, como aponta Gibson et al. (2008). Da mesma forma a dimensão "Pontos turísticos" sozinha explicou menos a variância total dos dados que a "Situação política". Isso indica que a situação política do país, apesar de aparentemente não parecer estar diretamente tão relacionada com a atividade turística e não ter aparecido na nova dimensão surgida "Visão generalista", é essencial na composição da imagem do destino. A dimensão "Visão generalista" foi a dimensão mais forte, 
incluindo questões tanto sobre "Segurança" e "Pontos turísticos", quanto sobre "Cultura". Isso indica que a imagem do destino é explicada por uma percepção geral sobre o mesmo, que inclui uma série de variáveis.

\section{COMPARAÇÃO DE MÉDIAS}

Feita a análise fatorial, os fatores resultantes foram utilizados para realizar uma comparação das suas médias. Essa comparação foi feita para observar quais dimensões foram mais bem avaliadas pelos respondentes e a existência de diferenças de avaliação de acordo com o gênero e a experiência com o Brasil.

\section{COMPARAÇÃO ENTRE AS DIMENSÕES}

Inicialmente, foi feita uma média entre as sentenças componentes de cada fator em cada uma das respostas do questionário, de modo que fosse criada uma média para cada um dos 5 fatores. Realizou-se, então, uma análise descritiva de comparação de médias, resultando nas médias de cada dimensão de imagem do Brasil (Tabela 4).

Tabela 4 - Análise descritiva de comparação de médias

Estatística Descritiva

\begin{tabular}{c|c|c|c|c|c|c|c|c|c}
\hline & $\mathrm{N}$ & Interva-lo & $\begin{array}{c}\text { Míni- } \\
\text { mo }\end{array}$ & Máximo & Soma & \multicolumn{2}{|c|}{ Média } & $\begin{array}{c}\text { Desvio } \\
\text { Padrão }\end{array}$ & Variância \\
\cline { 2 - 9 } & $\begin{array}{c}\text { Esta- } \\
\text { tístico }\end{array}$ & $\begin{array}{c}\text { Estatís- } \\
\text { tico }\end{array}$ & $\begin{array}{c}\text { Esta- } \\
\text { tístico }\end{array}$ & $\begin{array}{c}\text { Estatís- } \\
\text { tico }\end{array}$ & Estatístico & $\begin{array}{c}\text { Estatís- } \\
\text { tico }\end{array}$ & $\begin{array}{c}\text { Erro } \\
\text { Padrão }\end{array}$ & $\begin{array}{c}\text { Estatís- } \\
\text { tico }\end{array}$ & $\begin{array}{c}\text { Estatís- } \\
\text { tica }\end{array}$ \\
\cline { 2 - 10 } $\begin{array}{c}\text { Pontos } \\
\text { Turísticos }\end{array}$ & 107 & 5,50 & 1,50 & 7,00 & 615,50 & 5,7523 & 0,09630 & 0,99616 & 0,992 \\
$\quad$ Visão \\
$\begin{array}{c}\text { Generalista } \\
\text { Cultura }\end{array}$ & 107 & 4,67 & 2,33 & 7,00 & 601,83 & 5,6246 & 0,08742 & 0,90425 & 0,818 \\
$\begin{array}{c}\text { Segurança } \\
\text { Situação }\end{array}$ & 107 & 4,67 & 2,00 & 6,67 & 505,67 & 4,7259 &, 09262 & 0,95804 & 0,918 \\
Política & 107 & 3,40 & 2,20 & 5,60 & 416,80 & 3,8953 &, 07499 & 0,77574 & 0,602 \\
$\begin{array}{c}\text { N Válido } \\
\text { (listwise) }\end{array}$ & 107 & 5,25 & 1,00 & 6,25 & 328,50 & 3,0701 &, 10008 & 1,03523 & 1,072 \\
\hline
\end{tabular}

Fonte: Autoras, 2016.

A Tabela 4 apresenta uma ordenação descendente das médias das dimensões de imagem do Brasil como sede de megaeventos. Verifica-se que a dimensão 
mais bem avaliada pelos respondentes foi "Pontos Turísticos", com uma média de 5,75. Esse resultado encontra respaldo, pois, de acordo com Nadeau et al. (2008), atributos estudados em pesquisas de imagem são crenças sobre o ambiente natural, atrações naturais, cenário, clima, avaliações da destinação como excitante e emocionante, e avaliação global. Alguns dos estereótipos em relação ao Brasil são relacionados a cidades, natureza e esporte, como Rio de Janeiro, São Paulo, Cristo Redentor, Copa Cabana, Rio Amazonas, praias, paraíso, sol e floresta tropical (Melo \& Mataruna, 2016). Dessa forma, a Hipótese 3 'A dimensão pontos turísticos é a dimensão melhor apreciada na avaliação da imagem do Brasil como sede de megaeventos' foi confirmada. Observa-se a importância dessa dimensão pelo fato de questões sobre "Pontos turísticos" também fazerem parte da dimensão "Visão generalista", que foi a mais forte na análise fatorial.

Analisando ainda a Tabela 4, é possível identificar a imagem que os franceses possuem do Brasil como sede de um megaevento em relação a ser uma imagem mais positiva ou negativa, de acordo com uma média geral para o país (lembrando que a escala utilizada foi de 1 a 7). Observando-se as médias das 5 dimensões, é possível constatar que apenas a dimensão "Situação Política" não possui uma média acima do ponto médio da escala (3,5), mas ficando próxima disso, com o valor de 3,07. As demais médias são "Pontos Turísticos", com 5,75; "Visão Generalista", com 5,62; "Cultura", com 4,72; e "Segurança", com 3,89. Assim, calculando uma média geral das dimensões da imagem do Brasil como sede de megaeventos, encontra-se o valor de 4,6, confirmando a Hipótese 1 'Os franceses possuem uma imagem positiva do Brasil como um país sede de um megaevento esportivo'. Apesar do resultado positivo da imagem, nota-se que o item "Segurança" ficou bem pouco acima do ponto médio da escala, dando um indicativo de ser um fator que necessita de melhorias, bem como a visão sobre a "Situação política". O que faz sentido, uma vez que a situação política de um país reflete na sua segurança.

COMPARAÇÃO POR GÊNERO

A comparação por gênero pode ser vista analisando a Tabela 5. 
Tabela 5 - Resumo da função split files por gênero

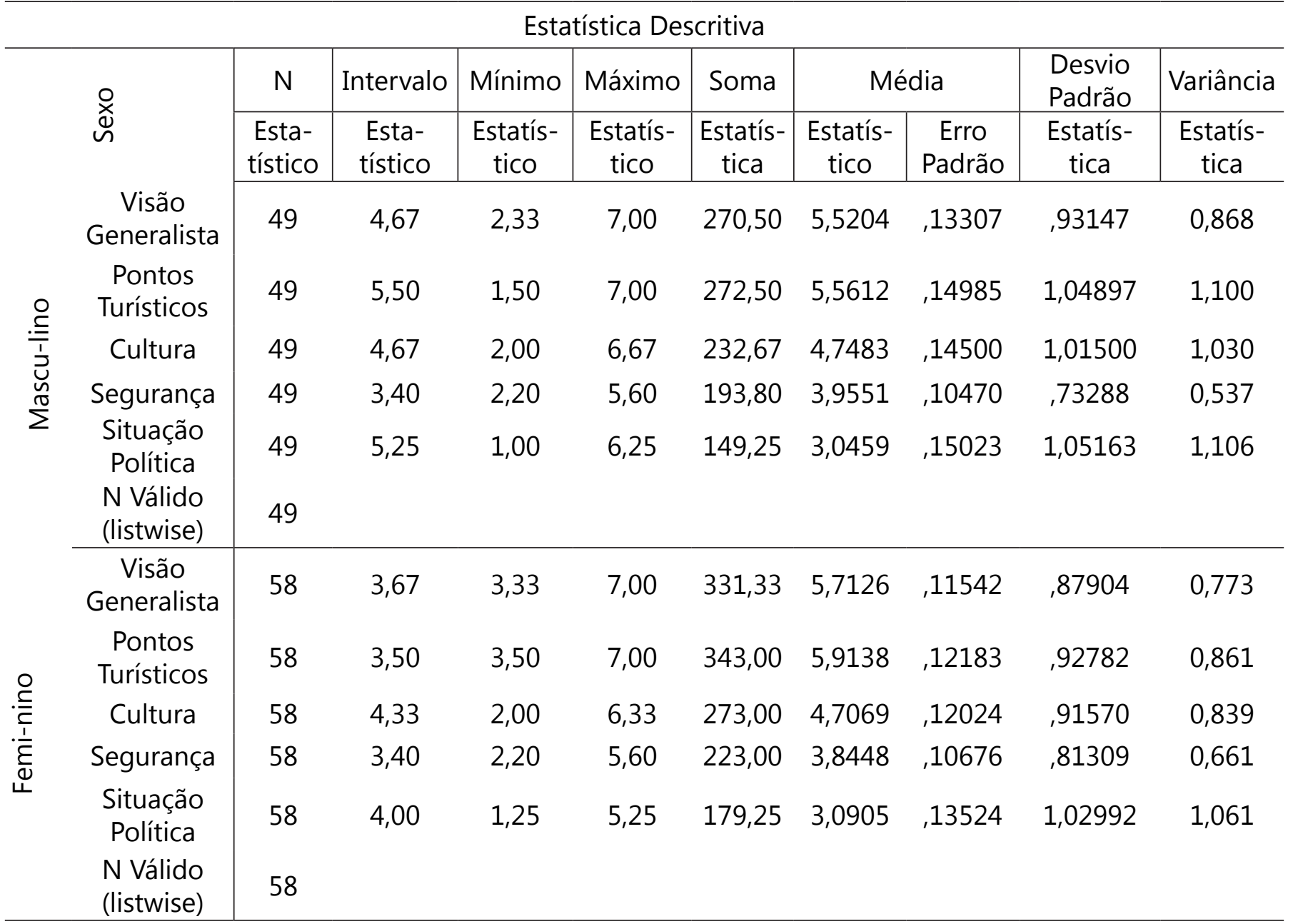

Fonte: Autoras, 2016.

Pode-se observar que as médias de três dimensões são maiores para o gênero feminino, tratando-se das médias resultantes das avaliações das mulheres para "Visão Generalista" (5,71), "Pontos Turísticos" $(5,91)$ e "Situação Política" $(3,09)$. Enquanto que para os homens, as dimensões "Cultura" e "Segurança" apresentaram médias mais altas, com 4,74 e 3,95 respectivamente. Porém, notase que as diferenças entre as médias das 5 dimensões, em relação aos gêneros, não são muito significativas, estando muito próximas às avaliações dadas por homens e mulheres.

Foi calculada uma média geral de avaliação da imagem do Brasil como sede de megaeventos esportivos para o gênero feminino e para o gênero masculino, de acordo com uma média das médias das dimensões. Apresentando uma média geral de 4,65 para as mulheres e uma média geral de 4,56 para os homens, observa-se que as médias gerais de avaliação da imagem do país são muito semelhantes para os dois sexos. Logo, a Hipótese 4, 'As pessoas do sexo 
feminino avaliam a imagem do Brasil como sede de grandes eventos mais positivamente do que as pessoas do sexo masculino', não foi confirmada. As mulheres avaliaram mais positivamente, mas a diferença foi muito pequena, de apenas 0,09, ou seja, homens e mulheres avaliaram de forma praticamente igual e positiva a imagem do Brasil como sede de grandes eventos. Esse resultado, de certa forma, vai ao encontro do apresentado na literatura, pois no estudo de Beerli e Martín (2004), foi encontrada uma melhor avaliação da imagem do destino por mulheres em alguns aspectos, mas não muito significativa.

\section{COMPARAÇÃO POR NÍVEL DE EXPERIÊNCIA ANTERIOR}

COM O BRASIL

Para verificar o nível de experiência com o país dos respondentes, foram propostas oito questões, uma de escala Likert de 1 a 7 , em que o pesquisado selecionava o grau de experiência com o país que ele possuía, e sete questões dicotômicas em que o respondente apresentava ter ou não algumas experiências específicas com o país.

Para classificar os participantes da amostra em alta ou baixa experiência anterior com o país, de acordo com suas respostas, foram estabelecidas as seguintes premissas: (1) Na pergunta de escala Likert, se a nota for maior ou igual a quatro, foi designado o 1 número para essa resposta, ficando 1 para alta experiência com o país e 0 para baixa experiência. (2) Nas questões dicotômicas, foi designado 1 para respostas "Sim" e 0 para respostas "Não", sendo as sentenças propostas para avaliação: ter visitado o Brasil, possuído contato direto com brasileiros no Brasil, possuído contato direto com brasileiro fora do Brasil, possuir amigo brasileiro, ter lido notícias sobre o Brasil, ter estudado sobre o Brasil e ter assistido a filme brasileiro ou sobre o Brasil. Feito isso, foi preciso dar uma classificação única para cada respondente, de modo que ele possuísse alta ou baixa experiência anterior com o país. Essa classificação foi feita com o somatório das respostas das oito questões propostas (a Likert e as dicotômicas), sendo 1 para experiência e 0 para não experiência, de modo que se a soma total fosse maior ou igual a quatro, a pessoa seria classificada como de alta experiência e, caso contrário, ela seria de baixa experiência. 
Utilizaram-se novamente as médias resultantes da análise descritiva de comparação de médias e a função split files do SPSS, pedindo para que a amostra fosse classificada de acordo com a experiência e que fosse separada em dois grupos, resultando, assim, em uma divisão da amostra de franceses de acordo com a alta ou a baixa experiência anterior com o Brasil e apresentando médias para cada uma das 5 dimensões de imagem em cada grupo, como mostra a Tabela 6.

Tabela 6 - Resumo da função split files por nível de experiência anterior com o Brasil

\begin{tabular}{|c|c|c|c|c|c|c|c|c|c|c|}
\hline \multicolumn{11}{|c|}{ Estatística Descritiva } \\
\hline \multicolumn{2}{|c|}{ Experiência } & \multirow{2}{*}{$\frac{N}{\text { Est. }}$} & \multirow{2}{*}{$\begin{array}{l}\text { Inter- } \\
\text { valo } \\
\text { Esta- } \\
\text { tística }\end{array}$} & \multirow{2}{*}{$\begin{array}{c}\text { Min } \\
\text { Esta- } \\
\text { tístico }\end{array}$} & \multirow{2}{*}{$\begin{array}{c}\text { Max } \\
\text { Esta- } \\
\text { tístico }\end{array}$} & \multirow{2}{*}{$\begin{array}{c}\text { Soma } \\
\begin{array}{c}\text { Estatís- } \\
\text { tica }\end{array}\end{array}$} & \multicolumn{2}{|c|}{ Média } & \multirow{2}{*}{$\begin{array}{c}\text { Desvio } \\
\text { Padrão } \\
\begin{array}{c}\text { Estatís- } \\
\text { tica }\end{array}\end{array}$} & \multirow{2}{*}{$\begin{array}{l}\text { Vari- } \\
\text { ância } \\
\text { Esta- } \\
\text { tística }\end{array}$} \\
\hline Experi & ncia & & & & & & $\begin{array}{l}\text { Esta- } \\
\text { tísica }\end{array}$ & $\begin{array}{c}\text { Erro } \\
\text { estatís- } \\
\text { tico }\end{array}$ & & \\
\hline \multirow{6}{*}{$\begin{array}{c}\text { Baixa } \\
\text { Experiência }\end{array}$} & Visão Gen. & 35 & 4,67 & 2,33 & 7,00 & 195,17 & 5,5762 & 0,16713 & 0,98878 & ,978 \\
\hline & $\begin{array}{l}\text { Situação } \\
\text { Política }\end{array}$ & 35 & 5,00 & 1,25 & 6,25 & 102,00 & 2,9143 & 0,16745 & 0,99066 & ,981 \\
\hline & Segurança & 35 & 2,80 & 2,60 & 5,40 & 130,60 & 3,7314 & 0,12433 & 0,73556 &, 541 \\
\hline & Cultura & 35 & 4,33 & 2,00 & 6,33 & 165,67 & 4,7333 & 0,16330 & 0,96609 & ,933 \\
\hline & $\begin{array}{l}\text { Pontos } \\
\text { Turísticos }\end{array}$ & 35 & 5,50 & 1,50 & 7,00 & 197,50 & 5,6429 & 0,19828 & 1,17305 & 1,376 \\
\hline & $\begin{array}{l}\text { N Válido } \\
\text { (listwise) }\end{array}$ & 35 & & & & & & & & \\
\hline \multirow{6}{*}{$\begin{array}{c}\text { Alta } \\
\text { Experiência }\end{array}$} & Visão Gen. & 72 & 3,67 & 3,33 & 7,00 & 406,67 & 5,6481 & 0,10212 & 0,86650 & 0,751 \\
\hline & $\begin{array}{l}\text { Situação } \\
\text { Política }\end{array}$ & 72 & 4,25 & 1,00 & 5,25 & 226,50 & 3,1458 & 0,12429 & 1,05463 & 1,112 \\
\hline & Segurança & 72 & 3,40 & 2,20 & 5,60 & 286,20 & 3,9750 & 0,09277 & 0,78718 & 0,620 \\
\hline & Cultura & 72 & 4,67 & 2,00 & 6,67 & 340,00 & 4,7222 & 0,11324 & 0,96089 & 0,923 \\
\hline & $\begin{array}{l}\text { Pontos } \\
\text { Turísticos }\end{array}$ & 72 & 3,50 & 3,50 & 7,00 & 418,00 & 5,8056 & 0,10631 & 0,90209 & 0,814 \\
\hline & $\begin{array}{l}\text { N Válido } \\
\text { (listwise) }\end{array}$ & 72 & & & & & & & & \\
\hline
\end{tabular}

Fonte: Autoras, 2016.

Analisando a Tabela 6, observa-se que as diferenças entre as médias das dimensões são bem pouco significativas entre os grupos de alta e baixa experiência. Em todas as dimensões o grupo de alta experiência possui média minimamente maior, com exceção de "Cultura", em que a média do grupo de baixa experiência excede em apenas 0,01 . A média geral do grupo com baixa experiência foi de 4,52 e a do grupo com alta experiência de 4,66, diferença muito pequena e consequentemente uma avaliação da imagem do Brasil muito semelhante. Com 
essa análise, a Hipótese 5 'As pessoas que possuem maior experiência com o Brasil, avaliam a imagem do Brasil como sede de grandes eventos mais positivamente do que as pessoas com menor experiência' não foi confirmada, pois embora a média de avaliação da imagem do Brasil pelos franceses com maior experiência tenha sido mais positiva, a diferença foi de apenas 0,14. Importante salientar que a maior experiência com o destino significa maior familiaridade com o mesmo, que pela literatura (Elliot et al., 2011) indica uma maior influência para uma percepção mais positiva, no entanto a diferença encontrada não foi significativa.

\section{CONCLUSÕES}

Esse trabalho buscou investigar a avaliação da imagem do Brasil como sede de grandes eventos por uma amostra de estudantes franceses, contribuindo para a agenda de estudos sobre imagem de destino turístico relacionada a megaeventos esportivos. Foi verificado que a amostra pesquisada possui uma imagem positiva do Brasil como sede de megaeventos, confirmando a Hipótese 1. Verificou-se que, de uma forma geral, a amostra tem uma impressão positiva do destino para sediar um megaevento, podendo essa avaliação ser um indício de que a amostra possui inclinação para visitar o país, tanto em megaeventos como para turismo em geral.

Além desse objetivo geral, outros objetivos parciais foram alcançados. As dimensões propostas na composição da imagem do Brasil indicadas na Hipótese 2 'Situação política, segurança, cultura e pontos turísticos' foram confirmadas, indo ao encontro do que é proposto pela literatura, além do aparecimento de uma quinta dimensão, "visão generalista sobre o país". O aparecimento dessa quinta dimensão contribui com perspectiva de formação de imagem baseada em aspectos cognitivos, afetivos e gerais.

Um dos pontos interessantes dos resultados foi a confirmação da Hipótese 3 'A dimensão pontos turísticos é a dimensão mais bem apreciada na avaliação da imagem do Brasil como sede de um megaevento esportivo'. Esse resultado contribui com a ideia de que, apesar de alguns fatores negativos apontados em pesquisa de imagem do Brasil como a de Melo e Matamura (2016) e as dificuldades de gerenciamento da imagem por ser um país em desenvolvimento, 
os diversos atributos turísticos do Brasil se sobressaem na sua imagem de destino, indicando um grande potencial, que pode ser também associado a megaeventos a serem realizados.

O estudo buscou ainda aprofundar sua análise por meio de comparações entre gênero e nível de experiência com o destino por meio das Hipóteses 4 e 5, que, no entanto, não foram confirmadas. Ressalta-se que a literatura tem indicado a experiência como um fator que contribui para uma melhor percepção sobre um destino, contudo os resultados encontrados neste estudo apontaram uma diferença pouco significativa. Igualmente aconteceu com o gênero. Sobre o gênero, talvez seja o caso de novas pesquisas, visto que na literatura pesquisada não foram encontrados muitos estudos que relacionassem essas diferenças e poucos com resultados significativos.

Este trabalho contribui para a literatura de imagem de destino e de megaeventos, sobretudo considerando o contexto de países com nível de desenvolvimento similar ao Brasil. De modo específico, sobre o país pesquisado, há poucas pesquisas sobre a temática, sobretudo com amostra estrangeira. Destaca-se também a possível aplicabilidade dos resultados encontrados por parte do governo, organizadores de megaeventos e demais partes interessadas em relação a fatores que precisam ser melhorados, de modo que o destino se torne mais competitivo. O trabalho contou com algumas limitações, como a escassez de trabalhos sobre a imagem do Brasil como sede de megaeventos como também de estudos sobre a imagem do Brasil em si e que fatores são relevantes. Como sugestão para estudos futuros, pode ser considerada a necessidade de mais discussões acerca dos fatores moderadores da formação da imagem de destino turístico, além de experiência e gênero. Aspectos como a animosidade em relação ao país e própria intenção de visitação. Além disso, esse trabalho trouxe um olhar de um público de uma nacionalidade específica, comparações de resultados entre nacionalidades diversas podem ser interessantes para estudos futuros ou mesmo comparação entre residentes e estrangeiros.

REFERÊNCIAS

Balabanis, G., Mueller, R. \& Melewar, T. C. (2002). The human values'lenses of country of origin images. International Marketing Review, 19, 582-610. 
Berkowitz, P., Gjermano, G.; Gomez, L. \& Schafer, G. (2007). Brand China: Using the 2008 Olympic Games to enhance China's image. Place Branding and Public Diplomacy, 3, 164-178.

Beerli, A. \& Martín, J. D. (2004). Factors influencing destination image. Annals of Tourism Research, 31(3), 657-681.

Brasil. Ministério do Turismo [Mtur]. (2017). Anuário estatístico 2017. Recuperado em 5 de abril de 2017 de: http://www.dadosefatos.turismo.gov.br/2016-02-04-11-53-05.html.

(2015). Mais de 6,4 milhões de turistas estrangeiros visitaram o Brasil em 2014. Recuperado em 15 de março de 2016 de: http://www.turismo.gov.br/ultimas-noticias/5227mais-de-6,4-milh\%C3\%B5es-de-turistas-estrangeiros-visitaram-o-brasil-em-2014.html.

(2016a). Receita cambial do turismo fecha 2016 com alta.. Disponível em: http:// www.turismo.gov.br/\%C3\%BAltimas-not\%C3\%ADcias/7455-receita-cambial-do-turismofecha-2016-com-alta.html. Acesso em: 09/02/2017.

(2016b). Recuperado em 01 de março de 2017 de: http://www.brasil.gov.br/ turismo/2016/08/eventos-internacionais-no-brasil-crescem-em-400.

Bresler, N. C. (2011). Tourist considerations in hosting a mega sport event: 2010 FIFA World Cup in South Africa. South African Journal for Research in Sport, Physical Education and Recreation, 33(2), 17-33.

Da Silva, A. C., Braga, D. C., \& Romano, F. S. (2016). Megaeventos e Turismo: um estudo bibliométrico dos periódicos brasileiros de turismo. Turismo-Visão e Ação, 18(3), 633-659.

Davies, G. (2009). Managing the alchemy of the 2010 Football World Cup. In Pillay, U., Tomlinson, R. \& Bass, O. (Eds.). Development and dreams: The urban legacy of the 2010 football World Cup. Cape Town: HSRC Press.

De Melo, L. M. (2011). Experiences from World Cup 2010 in South Africa-first thoughts about implication for Brazil 2014. Internationale Sportevents im Umbruch?, 51.

Deng, Q. \& Li, M. A. (2013). A model of event-destination image transfer. Journal of Travel Research, 53(1), $69-82$.

Dragin-Jensen, C. (2016). Mutual image impacts of events and host destinations: what we know from prior research, Department of Environmental and Business Economics Faculty of Business and Social Sciences, 122, 1-29.

Durand, A. (2016). Building a better literatura review: looking at the nomological network of the country-of-origin effect. Canadian Journal of Administrative Sciences, 33, 50-65. 
Du Plessis, S. \& Maenning, W. (2011). The 2010 FIFA World Cup high-frequency data economics: effects on international tourism and awareness for South Africa. Development Southern Africa, 28(3), 349-365.

Elliot, S., Papadopoulos, N. \& Kim, S. S. (2011). An integrative model of place image: exploring relationships between destination, product, and country images. Journal of Travel Research, 50(5), 520-534.

Fourie, J. \& Gallego, M. S. (2011). The impact of mega-sport events on tourist arrivals. Tourism Management, 32, 1364-1370, 2011.

Gibson, H. J., Qi, C. X. \& Zhang, J. J. (2008). Destination image and the intent to visit China and the 2008 Beijing Olympic Games. Journal of Sport Management, 22, 427-450

G1 Rio. Recuperado em 01 de outubro de 2016 de: http://g1.globo.com/rio-de-janeiro/ olimpiadas/rio2016/noticia/2016/08/ prefeitura-faz-balanco-da-olimpiada-e-paes-dizque-o-rio-calou-criticos.html.

Hair, J. F., Black, W. C., Babin, B. J.; Anderson, R. E., \& Tatham, R. L. (2009). Análise multivariada de dados. Bookman.

Jaffe, E. \& Nebenzah, I. (1993). Global Promotion of Country Image: Do the Olympics Count? In Product-Country Images: Impact and Role. In: International Marketing, N. Papadopoulos and L. Heslop, eds.: 433-452. Binghamtom: International Business Press.

Kaplanidou, K. \& Vogt, C. (2007). The Interrelationship between Sport Event and Destination Image and Sport Tourists' Behaviours. Journal of Sport \& Tourism, 12(3-4), 183- 206.

Kim, H. J., Gursoy, D. \& Lee, S. B. (2006). The impact of the 2002 World Cup on South Korea: comparisons of pre- and post-Games. Tourism Management, 27(1), 86-96

Knott, B., Fyall, A. \& Jones, I. (2015). The nation branding opportunities provided by a sport mega-event: South Africa and the 2010 FIFA World Cup. Journal of Destination Marketing \& Management, 4, 46-56.

Korstanje, M. E., Tzanelli, R. \& Clayton, A. (2014). Brazilian World Cup 2014: terrorism, tourism, and social conflict. Event Management, 18(4), 487-491.

Lee, C., Lee, Y. \& Lee, B. (2005a). Korea's destination image formed by the 2002 World Cup. Annals of Tourism Research, 32(4), 839-858.

Lee, C. K., Taylor, T., Lee, Y. K. \& Lee, B. (2005b). The impact of a sport mega-event on destination image: The case of the 2002 FIFA World Cup Korea/Japan. International Journal of Hospitality \& Tourism Administration, 6(3), 27-45. 
Li, S. N., Blake, A. \& Cooper, C. (2011). Modelling the economic impact of international tourism on the Chinese economy: a CGE analysis of the Beijing 2008 Olympics. Tourism Economics, 17(2), 279-303.

Lima, L. (2014). Governo espera superar meta de 600 mil turistas estrangeiros na Copa. IG Brasília. Recuperado em 15 de abril de 2016 de: http://copadomundo.ig.com.br/2014-0709/governo-espera-superar-meta-de-600-mil-turistas-estrangeiros-na-copa.html.

Malhotra, N. (2012). Pesquisa de Marketing: uma orientação aplicada. (6 $6^{\mathrm{a}}$ ed.). Porto Alegre: Bookman

Matos, N., Mendes, J. \& Valle, P. O. D. (2012). Revisiting the destination image construct through a conceptual model. Dos Algarves: A multidisciplinar e-journal, 21, 101-117.

Melo, T. \& Mataruna, L. (2016). The Image of Brazil and Rio de Janeiro as a Tourist Destination: Results of a Pilot Study on Foreigners' Intentions to Attend the 2016 Olympic Games. Publication name, 352.

Moon, K. S., Kim, M., Jae Ko Y., Connaughton, D. P. \& Hak Lee, J. (2011). The influence of consumer's event quality perception on destination image. Managing Service Quality: An International Journal, 21(3), 287-303.

Moon, K. S., Jae Ko, Y. J., Connaughton, D. P. \& Lee, J. H. (2013). A mediating role of destination image in the relationship between event quality, perceived value, and behavioral intention. Journal of Sport \& Tourism, 18(1), 49-66.

Nadeau, J., Heslop, L., O’Reilly, N. \& Luk, P. (2008). Destination in a country image context. Annals of tourism Research, 35(1), 84-106.

Rezend-Parker, A., Morrison, A. M. \& Ismail, J. A. (2003). Dazed and confused? An exploratory study of the Brazil as a travel destination. Journal of Vacation Marketing, 9, 243-259.

Roche, M. (2000). Mega-events and modernity: Olympics and expos in the growth of global culture. Routledge, London. Chp, .1, 1-30.

Roth, K. P. \& Diamantopoulos, A. (2009). Advancing the country image construct. Journal of Business Research, 62, 726-740.

Swart, K., George, R., Cassar, J. \& Sneyd, C. (2017). The 2014 FIFA World Cup ${ }^{\mathrm{TM}}$ : Tourists' satisfaction levels and likelihood of repeat visitation to Rio de Janeiro. Journal of Destination Marketing \& Management.

Tasci, A. D. A. \& Kozak, M. (2006). Destination brands vc destination images: do we know what we mean? Journal of Vacation Marketing, 12, 299-317. 
Tasci, A. D. A., Gartner, W. C. \& Cavusgil, S. T. (2007). Conceptualization and Operationalization of Destination Image. Journal of Hospitality \& Tourism Research, 31(2), 194-223.

Tavares, O. (2005). Quem são os vencedores e os perdedores dos jogos olímpicos? Pensar a prática, 8(1), 69-84.

Tomlinson, R., Bass, O. \& Bassett, T. (2011). Before and after the vuvuzela: identity, image and mega-events in South Africa, China and Brazil. South African Geographical Journal, 93(1), 38-48.

The New York Times. (2016). Facing Impeachment, Dilma Rousseff Fights for Political Survival. Recuperado em 18 de abril de 2016 de: http://mobile.nytimes.com/2016/04/19/ opinion/dilma-rousseffs-fight- for-political-survival.html?rref=collection\%2Ftimestopic\%2 FRousseff\% 2C\%20Dilma\&action=click\&contentCollection=timestopics.

Walker, M., Kaplanidou, K., Gibson, H., Thapa, B. Geldenhuys, S. \& Coetzee, W. (2013). Win in Africa, with Africa: Social responsibility, event image, and destination benefits. The case of the 2010 FIFA World Cup in South Africa. Tourism Management, 34, 80-90.

Verlegh, P. W. \& Steenkamp, J. B. E. (1999). A review and meta-analysis of country-oforigin research. Journal of economic psychology, 20(5), 521-546.

\section{CONTRIBUIÇÃO DOS AUTORES NA CONSTRUÇÃO DO ARTIGO}

OLIVIERI: Realizou revisão da literatura, participou da coleta e da análise dos dados e da redação das conclusões.

GIRALDI: Coordenou a pesquisa, realizou análise dos dados e revisou todo o texto.

FERREIRA: Realizou revisão da literatura, participou da redação das análises e das conclusões. 